\title{
A New Class of Alkoxyamines for Efficient Controlled Homopolymerization of Methacrylates
}

Nicholas Ballard, ${ }^{1}$ Miren Aguirre, ${ }^{1}$ Alexandre Simula, ${ }^{l}$ Amaia Agirre, ${ }^{1}$ Jose R. Leiza, ${ }^{{ }^{*}}$ José M. Asua ${ }^{1}$ and Steven van Es ${ }^{1,2} *$

1. POLYMAT and Kimika Aplikatua Saila, University of the Basque Country UPV/EHU, Joxe Mari Korta Zentroa, Tolosa Hiribidea 72, 20018, Donostia/San Sebastián, Spain

2. Dispoltec BV, PO Box 331, 6160 AH Geleen, The Netherlands 


\section{Experimental}

\section{Materials}

Methyl methacrylate (MMA, Quimidroga, technical grade) and styrene (Quimidroga, technical grade) were purified by distillation and were kept at $-20{ }^{\circ} \mathrm{C}$ until use. Butyl methacrylate (BMA, Aldrich, 99\%) was filtered through a column of basic alumina before use. Benzyl bromide (Aldrich, 98\%), cyclohexylamine (Aldrich, 99\%), tert-butylamine (Aldrich, 98\%), chloroacetonitrile (Aldrich, 99\%), sodium sulfate (Aldrich, 99\%), sodium bicarbonate (Aldrich, 99\%), potassium peroxymonosulfate (Oxone ${ }^{\circledR}$, Aldrich), formalin (37 wt \% solution of formaldehyde in water, Aldrich), sodium metabisulfite (Aldrich, 99\%), sodium cyanide (Aldrich, 97\%), 2,6-Di-tert-butyl- $\alpha-(3,5-$ di-tert-butyl-4-oxo-2,5cyclohexadien-1-ylidene)-p-tolyloxy (galvinoxyl, Aldrich) and 2,2'-azobis(2methylpropionitrile) (AIBN, Aldrich, 98\%) were used without further purification. Azoinitiator 2,2'-azobis(2-ethylbutyronitrile) (AEBN) was prepared according to Dox $J . A m$. Chem. Soc. 1925, 47, 1471-7. All other solvents were purchased from Scharlab, were of technical grade, and were used without purification.

\section{Methods}

For alkoxyamine syntheses NMR spectra were recorded on a Bruker Avance DPX 300 spectrometer in $\mathrm{CDCl}_{3}$ as solvent at $298 \mathrm{~K}$ or, for fully characterizing alkoxyamines III and IV, in toluene- $d 8$ at $368 \mathrm{~K}$ (because of strong broadening when recorded at ambient temperature). For conversion measurements NMR spectra were recorded on a Bruker Avance DPX 400. The melting points of the synthesized alkoxyamines were determined using a Büchi Melting Point B-450. Molecular weight distributions of polymers were 
measured by size exclusion chromatography (SEC). Samples were dried and diluted in THF (HPLC grade) to a concentration of approximately $5 \mathrm{mg} \cdot \mathrm{ml}^{-1}$ and filtered through a $0.45-$ $\mu \mathrm{m}$ nylon filter. The SEC set up consisted of a pump (LC-20A, Shimadzu), an autosampler (Waters 717), a differential refractometer (Waters 2410) and three columns in series (Styragel HR2, HR4 and HR6 with pore sizes ranging from $10^{2}$ to $10^{6} \AA$ ). Chromatograms were obtained in THF (HPLC grade) at $35{ }^{\circ} \mathrm{C}$ using a flow rate of $1 \mathrm{ml} \cdot \mathrm{min}^{-1}$. The equipment was calibrated using narrow MWD polystyrene standards ranging from 595 to $3.95 \times 10^{6} \mathrm{Da}\left(5^{\text {th }}\right.$ order universal calibration). UV measurements were recorded on a Shimadzu UV-2550 spectrometer.

\section{Alkoxyamine Synthesis}

\section{(Z)-N-(Cyanomethylene)-2-methylpropan-2-amine Oxide.}

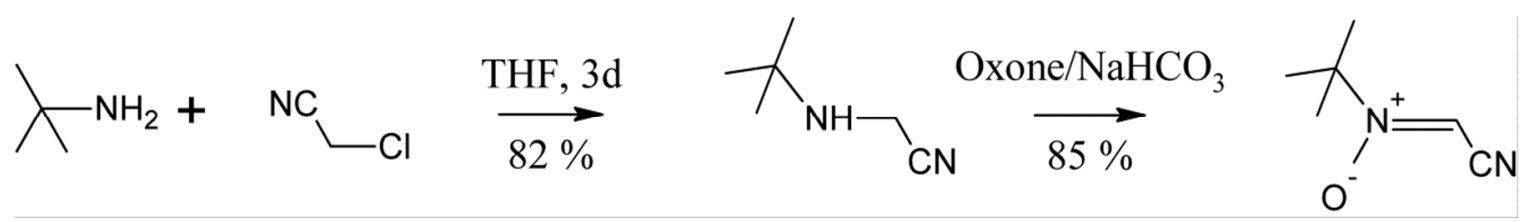

Step 1: Into a 500-mL Erlenmeyer flask with stirrer bar were charged $252 \mathrm{~mL}$ (3 equiv) of tert-butylamine and $150 \mathrm{~mL}$ of tetrahydrofuran and the flask was cooled in a water bath. To this was added drop wise $60.4 \mathrm{~g}(50.6 \mathrm{~mL}, 0.8 \mathrm{~mol})$ of chloroacetonitrile in ca. $30 \mathrm{~min}$ and the resulting mixture was left to stand for 3 days at room temperature. The reaction mixture was then filtered with the aid of $250 \mathrm{~mL}$ of ethyl acetate. The filtrate was washed with water, brine, dried over sodium sulfate, and after filtration the volatiles were evaporated to yield $73.6 \mathrm{~g}(82 \%)$ of a colorless liquid of greater than $98 \%$ purity $\left({ }^{1} \mathrm{H} \mathrm{NMR}\right)$ and suited as such for further use. ${ }^{1} \mathrm{H}$ NMR $\delta 1.11(\mathrm{~s}, 9 \mathrm{H}, t-\mathrm{Bu}), 1.17(\mathrm{br}, 1 \mathrm{H}, \mathrm{N}-\mathrm{H}), 3.53$ $\left(\mathrm{s}, 2 \mathrm{H}, \mathrm{CH}_{2}\right) ;{ }^{13} \mathrm{C}$ NMR $\delta 28.91(t-\mathrm{Bu}), 31.17\left(\mathrm{CH}_{2}\right), 51.51(\mathrm{C}-\mathrm{N}), 119.90(\mathrm{C} \equiv \mathrm{N})$. 
Step 2: The product of Step 1 dissolved in $450 \mathrm{~mL}$ of acetone was added to a 2-L beaker containing a mechanically stirred solution/suspension of $250 \mathrm{~g}$ of sodium bicarbonate in $450 \mathrm{~mL}$ of water. $460 \mathrm{~g}$ of Oxone ${ }^{\circledR}$ (1.13 mole equiv) was added in small portions of ca. 10 g over the course of $1 \mathrm{~h}$; small portions of crushed ice were occasionally added to maintain the reaction temperature below ca. $40{ }^{\circ} \mathrm{C}$. After Oxone ${ }^{\circledR}$ addition was complete, stirring was continued for $1 \mathrm{~h}$. Next, $400 \mathrm{~mL}$ of ethyl acetate was added, and after stirring for $5 \mathrm{~min}$ the mixture was allowed to phase separate, where after the top layer was decanted; this was repeated 3 times with $200 \mathrm{~mL}$ portions each of ethyl acetate. The combined organic phases were washed twice with brine, dried over sodium sulfate, and after filtration the solvents were evaporated to leave a reddish liquid that may crystallize on standing. Yield $70.6 \mathrm{~g}$ ( $85 \%$, or $70 \%$ over 2 steps). The product is sufficiently pure for further use. ${ }^{1} \mathrm{H}$ NMR $\delta$ $1.54(\mathrm{~s}, 9 \mathrm{H}, t-\mathrm{Bu}), 6.85(\mathrm{~s}, 1 \mathrm{H}, \mathrm{HC}=\mathrm{N}) ;{ }^{13} \mathrm{C} \mathrm{NMR} \delta 28.16(t-\mathrm{Bu}), 74.78(\mathrm{C}-\mathrm{N}), 103.88$ $(\mathrm{C}=\mathrm{N}), 112.98(\mathrm{C} \equiv \mathrm{N})$.

\section{Alkoxyamine I 3-(tert-Butyl(2-cyanopropan-2-yloxy)amino)-2,2-dimethylsuccinonitrile.}
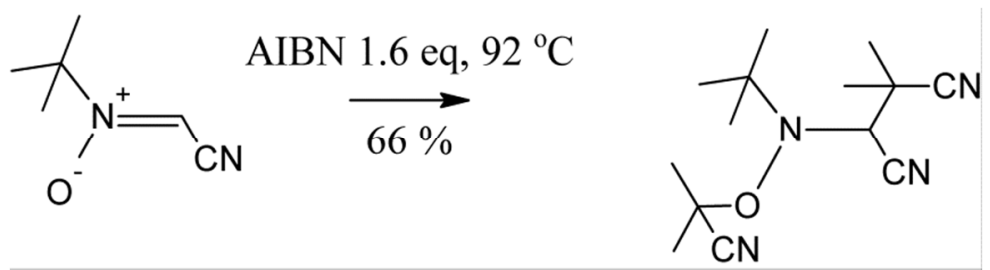

$18.92 \mathrm{~g}(0.15 \mathrm{~mol})$ of $(Z)-N$-(cyanomethylene)-2-methylpropan-2-amine oxide and $40.64 \mathrm{~g}$ (1.6 equiv) of $\mathrm{AIBN}$ in $250 \mathrm{~mL}$ of toluene were stirred at $92{ }^{\circ} \mathrm{C}$ (bath temp) for $6 \mathrm{~h}$. By evaporation of the solvent, then recrystallization from isopropanol and cooling in a refrigerator, ca. $80 \%$ of the alkoxyamine was recovered, contaminated by $10-20 \%$ tetramethylsuccinimide (TMSN). When this material was dissolved in hot isopropanol and 
the solution slowly cooled to room temperature, pure alkoxyamine was obtained. Yield: $26.0 \mathrm{~g}(66 \%) .{ }^{1} \mathrm{H}$ NMR $\delta 1.26(\mathrm{~s}, 9 \mathrm{H}, t$-Bu), 1.50, 1.61, 1.82 and 1.82 (each s, $3 \mathrm{H}, \mathrm{Me}$ ), $3.77(\mathrm{~s}, 1 \mathrm{H}, \mathrm{CH}-\mathrm{N}) ;{ }^{13} \mathrm{C}$ NMR $\delta 24.51,26.13,28.18$ and 28.18 (each Me), $26.61(t-\mathrm{Bu})$, $36.25\left(\underline{\left.\mathrm{CMe}_{2}\right),} 61.98(\mathrm{CH}-\mathrm{N}), 63.08(\mathrm{C}-\mathrm{N}), 76.58(\mathrm{C}-\mathrm{O}), 113.46,121.09\right.$ and 122.12 (each $\mathrm{C} \equiv \mathrm{N}$ ); Melting point range: $141-144{ }^{\circ} \mathrm{C}$; High resolution MS-ES calc. for $\mathrm{C}_{14} \mathrm{H}_{22} \mathrm{~N}_{4} \mathrm{ONa}[\mathrm{M}$ $+\mathrm{Na}]^{+}: 285.1691$; found: 285.1696.

\section{Alkoxyamine II 3-(tert-Butyl(3-cyanopentan-3-yloxy)amino)-2,2-diethylsuccinonitrile.}

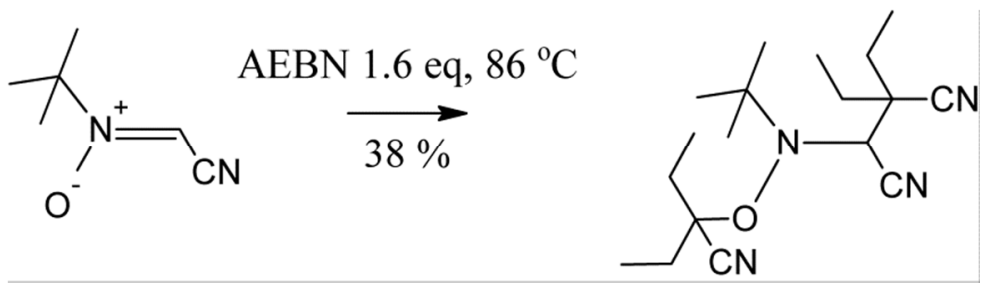

$5.68 \mathrm{~g}$ (45 mmol) of (Z)- $N$-(cyanomethylene)-2-methylpropan-2-amine oxide and $15.86 \mathrm{~g}$ (1.6 equiv) of AEBN in $75 \mathrm{~mL}$ of toluene were stirred at $86{ }^{\circ} \mathrm{C}$ (bath temp) overnight. NMR analysis indicated that conversion was close to $90 \%$ : beside the desired alkoxyamine as the main component small amounts of presumably nitroxide $(\delta 4.20)$ and of $\mathrm{NOH}$ compound, 3-(tert-butyl(hydroxy)amino)-2,2-diethylsuccinonitrile $(\delta 5.43(\mathrm{br}, \mathrm{NOH})$ and $3.90(\mathrm{CH}-\mathrm{N}))$, formed by disproportionation were present. Evaporation of solvent, then recrystallization from isopropanol and cooling in a freezer, gave after filtration $5.40 \mathrm{~g}$ (38\%) of alkoxyamine as needles. ${ }^{1} \mathrm{H}$ NMR $\delta 1.06,1.11,1.13$ and 1.18 (each t, $3 \mathrm{H}$, $\left.\mathrm{C}_{3} \mathrm{CH}_{2}\right), 1.28(\mathrm{~s}, 9 \mathrm{H}, t-\mathrm{Bu}), 1.55(\mathrm{~m}, 1 \mathrm{H}), 1.86-2.15(\mathrm{~m}, 5 \mathrm{H})$ and $2.18-2.34(\mathrm{~m}, 2 \mathrm{H})$ $\left(\mathrm{CH}_{3} \mathrm{C}_{2}\right), 4.04$ (s, $\left.1 \mathrm{H}, \mathrm{CH}-\mathrm{N}\right) ;{ }^{13} \mathrm{C}$ NMR $\delta 7.92,8.28,8.93$ and $9.13\left(\right.$ each $\left.\underline{\mathrm{CH}_{3}} \mathrm{CH}_{2}\right)$, 25.28, 28.24, 29.32 and 30.64 (each $\left.\mathrm{CH}_{3} \underline{\mathrm{CH}_{2}}\right), 26.98(t-\mathrm{Bu}), 45.38(\underline{\mathrm{CEt}} 2), 58.70(\mathrm{CH}-\mathrm{N})$, 
$63.88(\mathrm{C}-\mathrm{N}), 84.50(\mathrm{C}-\mathrm{O}), 113.96,119.45$ and 120.64 (each $\mathrm{C} \equiv \mathrm{N})$. Melting point range: 81 $83{ }^{\circ} \mathrm{C}$; High resolution MS-ES calc. for $\mathrm{C}_{18} \mathrm{H}_{30} \mathrm{~N}_{4} \mathrm{ONa}[\mathrm{M}+\mathrm{Na}]^{+}: 341.2317$; found: 341.2319 .

\section{(Z)-N-(Cyanomethylene)cyclohexanamine Oxide.}

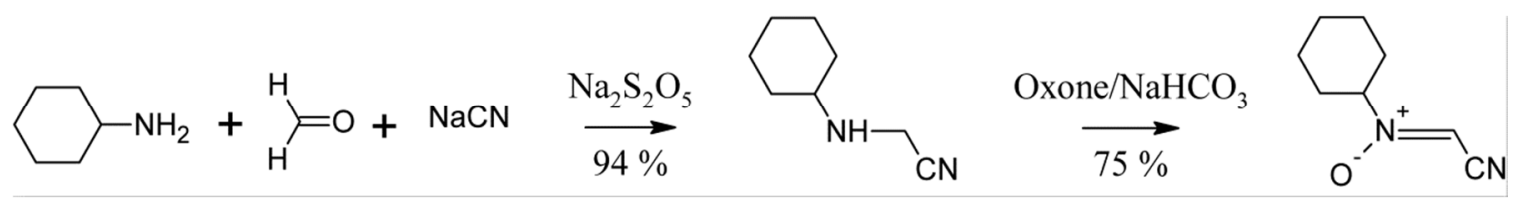

Step 1: To a solution of $125.3 \mathrm{~g}(0.66 \mathrm{~mol})$ of sodium metabisulfite in $200 \mathrm{~mL}$ of water was added $97.4 \mathrm{~g}$ of $\geq 37 \%$ formalin $(\geq 1.2 \mathrm{~mol}$ ) (caution: exothermic) and the solution was heated for $45 \mathrm{~min}$ at $70{ }^{\circ} \mathrm{C}$. After cooling to $60{ }^{\circ} \mathrm{C}, 126.0 \mathrm{~g}(1.27 \mathrm{~mol})$ of cyclohexylamine was rapidly added and stirring was continued for $0.5 \mathrm{~h}$ at that temperature. After cooling to room temperature, a solution of $62.5 \mathrm{~g}(1.275 \mathrm{~mol})$ of sodium cyanide in $250 \mathrm{~mL}$ of water was added drop wise in $1 \mathrm{~h}$, and stirring was continued for $4 \mathrm{~h}$. Water and toluene $(500 \mathrm{~mL}$ each) were added and the layers were separated. The aqueous layer was extracted once more with $250 \mathrm{~mL}$ of toluene. The combined organic layers were washed with water and with brine, dried over sodium sulfate, and after filtration the solvents were evaporated to give $155.9(94 \%)$ of the product as a colorless liquid that is sufficiently pure for the next step. It contains less than $2 \%$ of bis-alkylation product $(\delta 3.67) .{ }^{1} \mathrm{H}$ NMR $\delta 0.99-1.34(\mathrm{~m}, 6$ H) and 1.54-1.85 (m, $5 \mathrm{H})(\mathrm{c}-\mathrm{Hex}$ and $\mathrm{N}-\mathrm{H}), 2.64(\mathrm{tt}, 1 \mathrm{H}, \mathrm{CH}-\mathrm{N}), 3.58\left(\mathrm{~s}, 2 \mathrm{H}, \mathrm{CH}_{2} \mathrm{CN}\right)$;

${ }^{13} \mathrm{C}$ NMR $\delta 24.59,26.05,32.77$ and $34.49(c-\mathrm{Hex}), 55.32\left(\underline{\mathrm{C}}_{2} \mathrm{CN}\right), 118.30(\mathrm{C} \equiv \mathrm{N})$.

Step 2: according to the general recipe described in the first example with a slightly higher excess of sodium bicarbonate and Oxone ${ }^{\circledR}$ : using the crude product of Step 1 and $465 \mathrm{~g}$ of sodium bicarbonate in $600 \mathrm{~mL}$ each of acetone and water, then adding portion 
wise $850 \mathrm{~g}$ of Oxone ${ }^{\circledR}$ in $2 \mathrm{~h}$. Recrystallization from $n$-heptane-ethyl acetate $(3: 1 \mathrm{v} / \mathrm{v})$ gave a first crop of nitrone. Evaporation of the filtrate followed by recrystallization gave a second crop. Total yield: $126.2 \mathrm{~g}(75 \%)$ of $(Z)$-nitrone, containing typically less than 5\% $(E)$-isomer $(\delta 6.64) .{ }^{1} \mathrm{H}$ NMR $\delta 1.13-1.36(\mathrm{~m}, 3 \mathrm{H})$ and 1.60-2.04 (m, $\left.7 \mathrm{H}\right)(c$-Hex), $3.92(\mathrm{tt}$, $1 \mathrm{H}, \mathrm{CH}-\mathrm{N}), 6.79(\mathrm{~s}, 1 \mathrm{H}, \mathrm{HC}=\mathrm{N}) ;{ }^{13} \mathrm{C} \mathrm{NMR} \delta 24.71,24.75$ and $31.25(c-\mathrm{Hex}), 76.53(\mathrm{CH}-$ $\mathrm{N}), 105.26(\mathrm{HC}=\mathrm{N}), 112.66(\mathrm{C} \equiv \mathrm{N})$.

\section{Alkoxyamine III 3-(((2-Cyanopropan-2-yl)oxy)(cyclohexyl)amino)-2,2-dimethylsuccino-} nitrile.

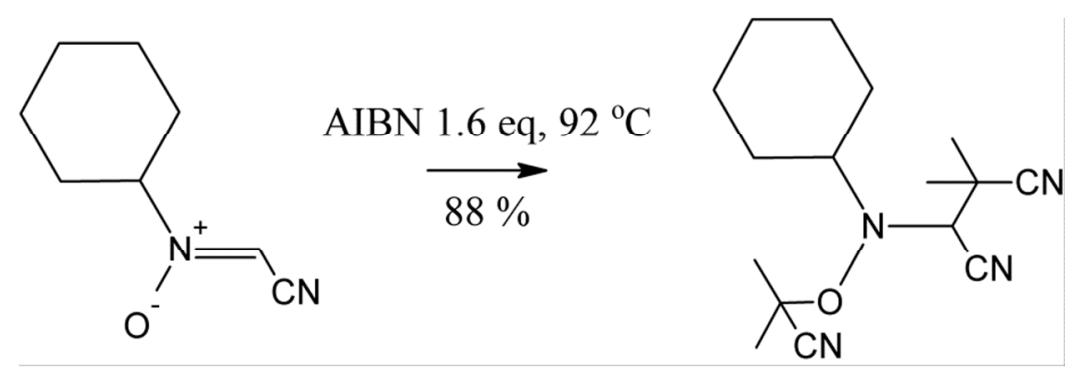

$45.66 \mathrm{~g}(0.3 \mathrm{~mol})$ of $(Z)-N$-(cyanomethylene) cyclohexanamine oxide and $81.3 \mathrm{~g}$ (1.65 equiv) of AIBN in $600 \mathrm{~mL}$ of isopropanol were stirred for $6 \mathrm{~h}$ at $92{ }^{\circ} \mathrm{C}$ (oil bath temperature). Heating and stirring were switched off, and the mixture was allowed to slowly cool to room temperature. The crystals were filtered on a Büchner funnel, washed with isopropanol and air dried. Yield: $76.15 \mathrm{~g}(88 \%)$ of pure alkoxyamine as white crystals. ${ }^{1} \mathrm{H}$ NMR $\delta 0.85-1.75(\mathrm{~m}, 9 \mathrm{H})$ and $2.45(\mathrm{~m}, 1 \mathrm{H})(c$-Hex), 1.19, 1.20, 1.28 and 1.38 (each s, $3 \mathrm{H}, \mathrm{Me}$ ), 3.36 (br tt, $1 \mathrm{H}, \mathrm{CH}-\mathrm{N} c-\mathrm{Hex}$ ), 3.54 (br s, $1 \mathrm{H}, \mathrm{CH}-\mathrm{N}) ;{ }^{13} \mathrm{C}$ NMR $\delta 24.92,25.85$, 26.03, 26.03, 26.30, 26.45, 27.08, 27.58 and $32.87(c$-Hex and $4 \mathrm{Me}), 36.25\left(\underline{\mathrm{CMe}}_{2}\right), 63.07$ and 65.77 (each $\mathrm{CH}-\mathrm{N}), 73.60(\mathrm{C}-\mathrm{O}), 114.86,121.55$ and $121.6($ each $\mathrm{C} \equiv \mathrm{N})$; Melting point 
range: $130-132^{\circ} \mathrm{C}$; High resolution MS-ES calc. for $\mathrm{C}_{16} \mathrm{H}_{25} \mathrm{~N}_{4} \mathrm{O}[\mathrm{M}+\mathrm{H}]^{+}: 289.2028$; found: 289.2040 .

\section{(Z)-N-Benzylidenecyclohexanamine Oxide.}

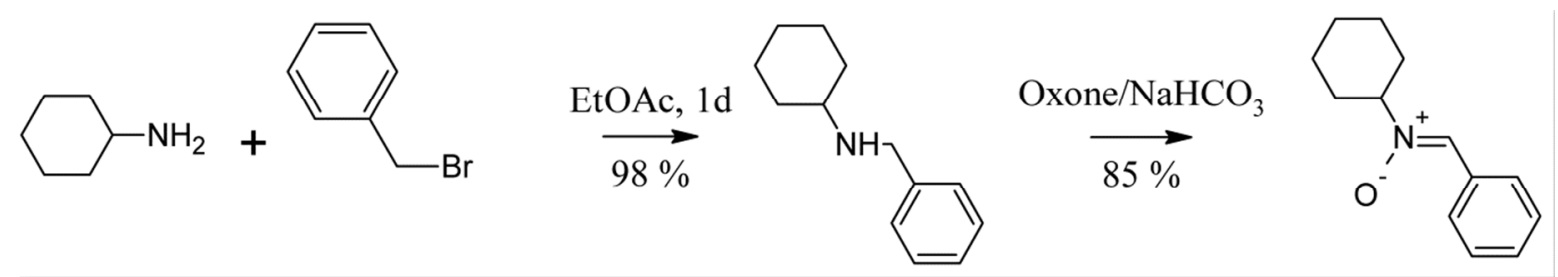

Step 1: into a 1-L Erlenmeyer flask with stirrer bar were charged $320 \mathrm{~mL}$ (3.5 equiv) of cyclohexylamine and $600 \mathrm{~mL}$ of ethyl acetate and the solution was cooled in an ice bath. To the stirred solution was added drop wise $136.8 \mathrm{~g}(95.1 \mathrm{~mL} ; 0.8 \mathrm{~mol})$ of benzyl bromide in ca. $1 \mathrm{~h}$ and the resulting mixture was stirred overnight at room temperature. The reaction mixture was filtered with the aid of $250 \mathrm{~mL}$ of toluene. The filtrate was washed with water and with brine, dried over sodium sulfate, and after filtration the volatiles were evaporated. Residual cyclohexylamine was removed by co-evaporation with toluene. This gave $186.6 \mathrm{~g}$ (98\%) of product as a colorless liquid that was sufficiently pure for the next step. It contained less than $3 \%$ of bis-alkylation product $(\delta 3.60) .{ }^{1} \mathrm{H}$ NMR $\delta 1.01-1.32(\mathrm{~m}, 6 \mathrm{H})$ and 1.53-1.93 (m, $5 \mathrm{H})\left(c-\mathrm{Hex}\right.$ and N-H), $2.46(\mathrm{tt}, 1 \mathrm{H}, \mathrm{CH}-\mathrm{N}), 3.78\left(\mathrm{~s}, 2 \mathrm{H}, \mathrm{CH}_{2} \mathrm{Ph}\right), 7.20-$ 7.55 (m, 5H, Ph); ${ }^{13} \mathrm{C}$ NMR $\delta 25.19,26.40$ and 33.77 (c-Hex), $51.25(\mathrm{CH}-\mathrm{N}), 56.36$ $\left(\mathrm{CH}_{2} \mathrm{Ph}\right), 126.96,128.23$ and $128.52(\mathrm{C}-\mathrm{H}, \mathrm{Ph}), 141.23(\mathrm{q}-\mathrm{C}, \mathrm{Ph})$.

Step 2: according to the general recipe described in the first example using the crude product of Step 1 and $300 \mathrm{~g}$ of sodium bicarbonate in $500 \mathrm{~mL}$ each of acetone and water, then adding portion wise $530 \mathrm{~g}$ of Oxone ${ }^{\circledR}$ gave crude nitrone in nearly quantitative yield. 
Recrystallization from $n$-heptane-ethyl acetate $(7: 1 \mathrm{v} / \mathrm{v})$ gave a first crop. Evaporation of the filtrate followed by recrystallization gave a second crop. Total yield: $132.5 \mathrm{~g}(85 \%)$ of nitrone as a single isomer. ${ }^{1} \mathrm{H}$ NMR $\delta 1.11-1.39(\mathrm{~m}, 3 \mathrm{H}), 1.60(\mathrm{~m}, 1 \mathrm{H})$ and 1.83-2.12 (m, $6 \mathrm{H})(c-\mathrm{Hex}), 3.79(\mathrm{tt}, 1 \mathrm{H}, \mathrm{CH}-\mathrm{N}), 7.28-7.38(\mathrm{~m}, 3 \mathrm{H}, \mathrm{Ph}), 7.38(\mathrm{~s}, 1 \mathrm{H}, \mathrm{HC}=\mathrm{N}), 8.21(\mathrm{~m}, 2$ $\mathrm{H}, \mathrm{Ph}) ;{ }^{13} \mathrm{C}$ NMR $\delta$ 25.12, 25.12 and $31.22(c-\mathrm{Hex}), 75.69(\mathrm{CH}-\mathrm{N}), 128.48,128.59$ and 130.06 (C-H, Ph), 130.95 (q-C, Ph), $132.19(\mathrm{HC}=\mathrm{N})$.

\section{Alkoxyamine IV 3-(((2-Cyanopropan-2-yl)oxy)(cyclohexyl)amino)-2,2-dimethyl-3-} phenylpropanenitrile.

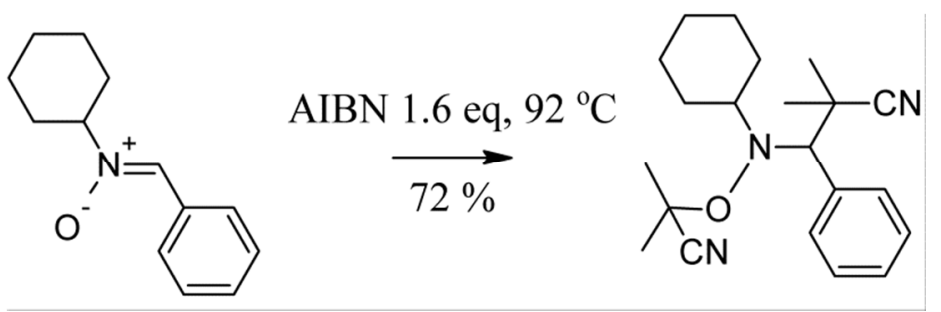

$24.39 \mathrm{~g}(0.12 \mathrm{~mol})$ of $(Z)$ - $N$-benzylidenecyclohexanamine oxide and $32.51 \mathrm{~g}$ (1.65 equiv) of AIBN in $250 \mathrm{~mL}$ of toluene were stirred at $92{ }^{\circ} \mathrm{C}$ (bath temp) for $6 \mathrm{~h}$. Evaporation of the solvent, re-dissolving the product in hot isopropanol and slowly cooling to room temperature, afforded a first crop. Evaporation of the filtrate and recrystallization from methanol afforded a second. Total yield: $29.44 \mathrm{~g}(72 \%)$ of crystalline alkoxyamine. ${ }^{1} \mathrm{H}$ NMR $\delta 0.74-$ 1.75 (m, $10 \mathrm{H}, c$-Hex), 0.91, 1.38, 1.49 and 1.57 (each s, $3 \mathrm{H}, \mathrm{Me}$ ), 3.54 (tt, $1 \mathrm{H}, \mathrm{CH}-\mathrm{N} c$ Hex), 3.5-4.2 (br, $1 \mathrm{H}, \mathrm{PhCH})$, 7.03-7.14 (m, $3 \mathrm{H})$ and 7.55-7.65 (m, $2 \mathrm{H})(\mathrm{Ph}) ;{ }^{13} \mathrm{C}$ NMR $\delta 26.39,26.47,26.71,26.81,27.26,27.39,28.32$ (br), 29.31 and 34.03 (br) (each C-H, $c$ Hex and $4 \mathrm{Me}$ ), 35.53 (므e $)$ ), 63.69 (C-H, c-Hex), 72.37 (C-O), 72.25 (br, PhCH), 122.47 and $124.84($ each $\mathrm{C} \equiv \mathrm{N}), 128.40,128.54$ and 131.13 (each $\mathrm{C}-\mathrm{H}, \mathrm{Ph}), 136.97$ (br q-C, Ph); 
Melting point range: $136-138^{\circ} \mathrm{C}$; High resolution MS-ES calc. for $\mathrm{C}_{21} \mathrm{H}_{30} \mathrm{~N}_{3} \mathrm{O}[\mathrm{M}+\mathrm{H}]^{+}$: 340.2389; found: 340.2394 .

\section{Methyl 3-(tert-butyl(1-methoxy-2-methyl-1-oxopropan-2-yloxy)amino)-3-cyano-2,2-} dimethylpropanoate.
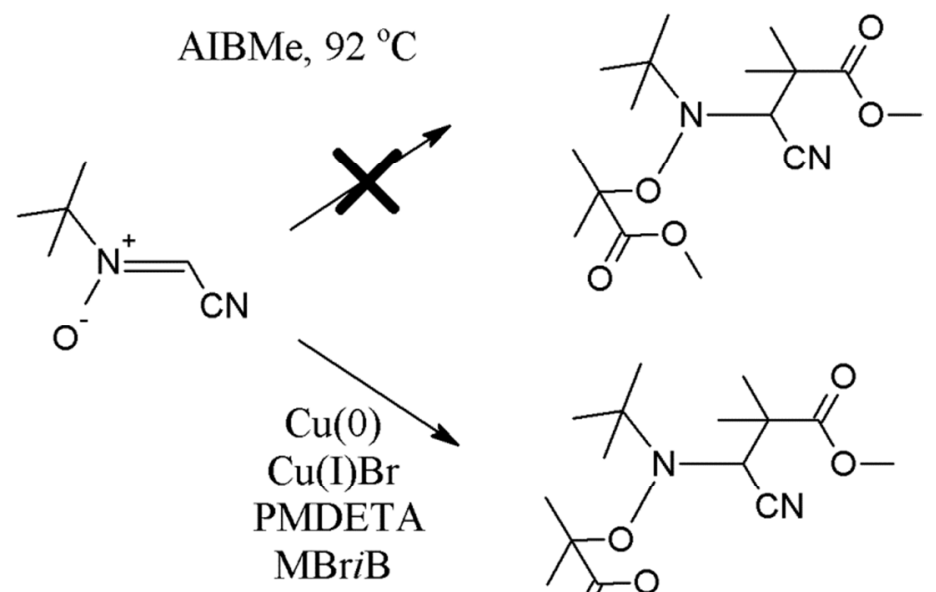

Procedure A. $5.68 \mathrm{~g}(45 \mathrm{mmol})$ of (Z)-N-(cyanomethylene)-2-methylpropan-2-amine oxide and $12.95 \mathrm{~g}$ (1.25 equiv) of dimethyl 2,2'-azobis(isobutyrate) (AIBMe) in $75 \mathrm{~mL}$ of toluene were stirred at $92{ }^{\circ} \mathrm{C}$ (bath temp) for $6 \mathrm{~h}$. The final conversion amounted to $92 \%$ of the nitrone, $75 \%$ being the desired alkoxyamine and $17 \%$ consisting of a 1:1 mixture of $2-$ (tert-butyl)-4,4-dimethyl-5-oxoisoxazolidine-3-carbonitrile $(\delta 4.06:$ s, $1 \mathrm{H}, \mathrm{H}-3)$ - formed by disproportionation of alkoxyamine to $\mathrm{NOH}$ compound followed by cyclization - and methyl 2-(tert-butyl)-3-cyano-5-methylisoxazolidine-5-carboxylate $(2.48,3.20$ and 3.96 : each dd, $1 \mathrm{H}, \mathrm{H}-3$ and H-4), formed by cycloaddition of starting nitrone to methyl methacrylate formed in the disproportionation. Isolation was not attempted.

Procedure B using Atom Transfer Radical Addition (ATRA). To $7.57 \mathrm{~g}$ (60 mmol) of (Z)-N-(cyanomethylene)-2-methylpropan-2-amine oxide and $30.2 \mathrm{~g}$ (2.9 equiv) of 
pentamethyldiethylenetriamine in $100 \mathrm{~mL}$ of nitrogen-flushed methanol was added a mixture of $16.25 \mathrm{~g}$ of copper(I) bromide and $2.70 \mathrm{~g}$ of copper powder (2.6 equiv of copper), To the stirred solution was added at room temperature in $0.5 \mathrm{~h}$ a solution of 27.15 $\mathrm{g}$ (2.5 equiv) of methyl $\alpha$-bromoisobutyrate in $20 \mathrm{~mL}$ of nitrogen flushed methanol and the reaction was stirred overnight, when starting nitrone had been completely converted. The reaction was poured into $250 \mathrm{~mL}$ of $50 \%$-saturated aqueous ammonium chloride and 250 $\mathrm{mL}$ of dichloromethane was added. After separation the water was extracted twice with 125-mL portions of dichloromethane. The combined organic fractions were washed twice with 50\%-saturated aqueous ammonium chloride, once with brine, dried over sodium sulfate, and after filtration solvents were removed in vacuum. The product was purified by flash column chromatography, followed by recrystallization from isopropanol to give a first crop of pure alkoxyamine. The filtrate was evaporated and again recrystallized from isopropanol to give a second crop. Combined yield: $12.62 \mathrm{~g}(64 \%)$ of white crystals. ${ }^{1} \mathrm{H}$ NMR $\delta 1.11(\mathrm{~s}, 9 \mathrm{H}, \mathrm{t}-\mathrm{Bu}), 1.28(\mathrm{~s}, 6 \mathrm{H}), 1.46(\mathrm{~s}, 3 \mathrm{H})$ and $1.49(\mathrm{~s}, 3 \mathrm{H})($ each Me), 3.66 and 3.68 (each s, $3 \mathrm{H}, \mathrm{OMe}), 4.28$ (s, $1 \mathrm{H}, \mathrm{CH}-\mathrm{N}) ;{ }^{13} \mathrm{C}$ NMR $\delta 21.77,23.88,24.28$ and 24.45

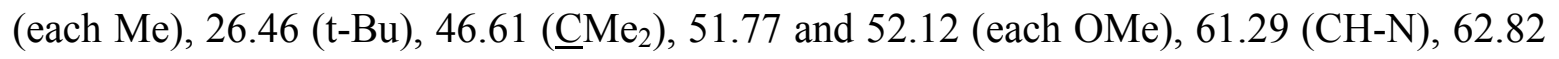
$(\mathrm{C}-\mathrm{N}), \quad 78.68(\mathrm{C}-\mathrm{O}), 115.80(\mathrm{C} \equiv \mathrm{N}), 174.57$ and $175.19 \quad($ each $\mathrm{C}=\mathrm{O})$. Attempted polymerization of methyl methacrylate using this alkoxyamine resulted in uncontrolled polymerization with a limiting conversion of $<70 \%$ (see Figure $\mathrm{S} 1$ ) and a static molecular weight of $M_{\mathrm{n}} \approx 5000 \mathrm{~g} / \mathrm{mol}$.

\section{Nitroxide-Mediated Polymerization}


Nitroxide-mediated polymerizations were carried out in solution in a $25-\mathrm{mL}$ round bottom flask. In a typical reaction, methyl methacrylate $(5 \mathrm{~g}, 50 \mathrm{mmol})$ was added to toluene $(5 \mathrm{~g})$ containing the alkoxyamine initiator, 3-(((2-cyanopropan-2-yl)oxy)(cyclohexyl)amino)-2,2dimethyl-3-phenylpropanenitrile $(163 \mathrm{mg}, 0.5 \mathrm{mmol})$, and the oxygen was removed by continuous nitrogen bubbling for 1 hour. The reaction mixture was heated to $90{ }^{\circ} \mathrm{C}$ in an oil bath with continuous stirring and left for $5 \mathrm{~h}$. At regular time intervals, a sample of $0.1 \mathrm{ml}$ was removed and diluted to $0.7 \mathrm{ml}$ with $\mathrm{CDCl}_{3}$ and the $\mathrm{NMR}$ spectrum was recorded. Fractional conversion, X, was measured by NMR by comparison of the integral of the vinyl protons at 5.6 and $6.2 \mathrm{ppm}$ to the combined signal of the $\mathrm{OCH}_{3}$ signals from both monomer and polymer at $3.8 \mathrm{ppm}$ and $3.7 \mathrm{ppm}$. Similarly, at the same time intervals, $0.1 \mathrm{ml}$ of the reaction mixture removed and dried in air. The resulting solid was dissolved in $5 \mathrm{ml}$ THF in order to perform the SEC measurements. After $6 \mathrm{~h}$ the polymer solution was precipitated in ice cold $\mathrm{MeOH}$ and the polymer was obtained by filtration and vacuum dried $\left(\mathrm{X}=0.68, M_{\mathrm{n}}\right.$ $=8100$ g.mol $\left.{ }^{-1}, Ð=1.49\right)$.

\section{Block Copolymer Synthesis}

To $500 \mathrm{mg}$ of pMMA homopolymer (see above) was added $1 \mathrm{~g}$ of butyl methacrylate. After stirring at room temperature until the polymer had dissolved completely, oxygen was removed by continuous nitrogen bubbling for 1 hour. The reaction mixture was heated to $90{ }^{\circ} \mathrm{C}$ in an oil bath with continuous stirring and left for $4 \mathrm{~h}$ at which point the conversion was measured by NMR and the polymer was precipitated in $\mathrm{MeOH}$ and the polymer was obtained by filtration and vacuum dried $\left(\mathrm{X}=0.35, M_{\mathrm{n}}=19800 \mathrm{~g} \cdot \mathrm{mol}^{-1}, Ð=1.46\right)$. 
An additional experiment was conducted using a pMMA macroinitiator synthesized at 96 ${ }^{\circ} \mathrm{C}$. MMA (5 g), toluene (5 g) and 3-(((2-cyanopropan-2-yl)oxy)(cyclohexyl)amino)-2,2dimethyl-3-phenylpropanenitrile (169 mg) were deoxygenated by purging with $\mathrm{N}_{2}$ and the reaction mixture was placed in an oil bath at $96{ }^{\circ} \mathrm{C}$. After $4 \mathrm{~h}$ the polymer solution was diluted with THF, then precipitated in ice cold $\mathrm{MeOH}$ and the polymer was obtained by filtration and vacuum dried $\left(\mathrm{X}=0.72, M_{n}=11000 \mathrm{~g} \cdot \mathrm{mol}^{-1}, D=1.29\right)$. The pMMA homopolymer (777 mg) was dissolved in a mixture of butyl methacrylate $(3 \mathrm{~g})$ and toluene

(3 g). The reaction was heated to $94{ }^{\circ} \mathrm{C}$ for overnight at which point the polymer was precipitated in ice cold $\mathrm{MeOH}$ and the polymer was obtained by filtration and vacuum dried $\left(X=0.20, \mathrm{M}_{\mathrm{n}}=18000 \mathrm{~g} \cdot \mathrm{mol}^{-1}, \oslash=1.25\right)($ see Figure $\mathrm{S} 8)$.

\section{Online NMR experiments}

Alkoxyamine IV (17 mg, $0.05 \mathrm{mmol})$ was dissolved in a mixture of methyl methacrylate $(0.5 \mathrm{~g}, 5 \mathrm{mmol})$ and toluene- $\mathrm{d}_{8}$. The mixture was transferred into a NMR tube equipped with a Young valve. Oxygen was removed by bubbling with nitrogen and the tube was sealed and stored in an ice bath until it was added to the preheated spectrometer at $90{ }^{\circ} \mathrm{C}$. ${ }^{1}$ H NMR spectra were recorded every 10 minutes for 800 minutes.

\section{Measurement of $\boldsymbol{k}_{d}$}

The rate coefficient of decomposition of the various alkoxyamines was measured by radical trapping experiments using galvinoxyl. $p$-Xylene $(2 \mathrm{ml})$ was placed in a quartz cuvette and nitrogen was bubbled through for 5 minutes. The cuvette was sealed with a rubber septum and heated to the desired temperature within a temperature control unit. The temperature was left to equilibrate for 20 minutes and $175 \mu \mathrm{l}$ of $1 \mathrm{mM}$ solution of galvinoxyl in xylene 
was injected via syringe. Then, $175 \mu \mathrm{l}$ of a $1 \mathrm{mM}$ solution of alkoxyamine was injected via syringe. The UV absorbance at $407 \mathrm{~nm}$ was measured continuously. The rate coefficient was calculated by plotting the change in absorbance A with time according to

$-\ln \left(\frac{A}{A_{0}}\right)=k_{d} t$

The measurements were repeated at 50,60 and $70{ }^{\circ} \mathrm{C}$ in order to yield the Arrhenius parameters. 

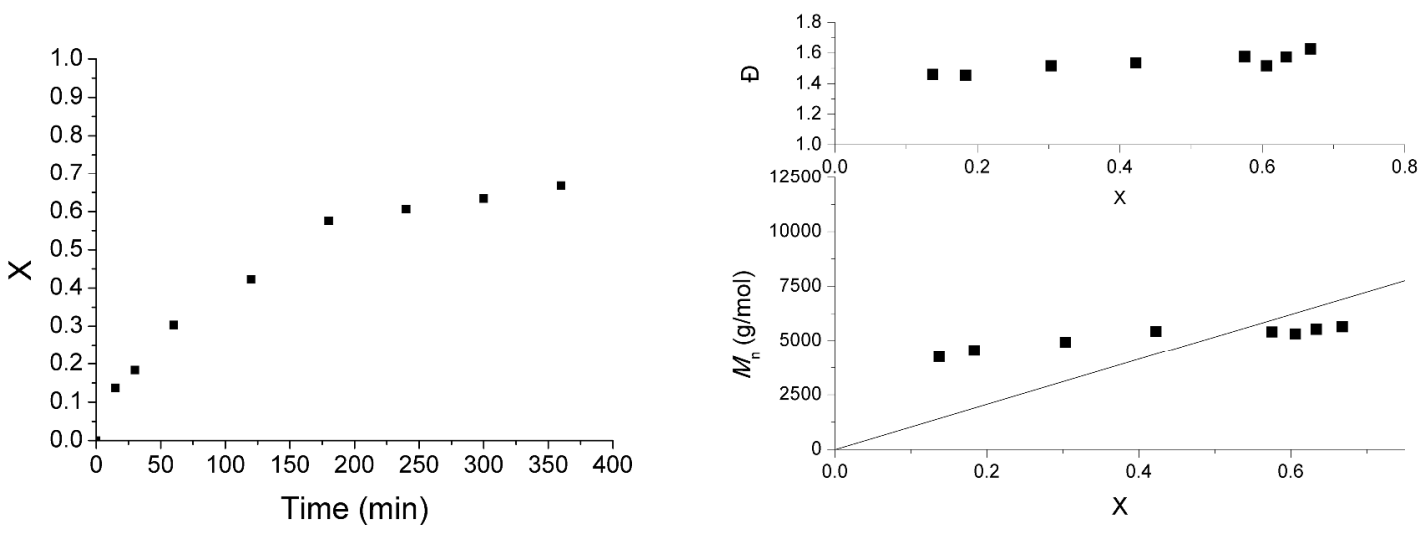

Figure S1 Evolution of conversion with time (left) and evolution of $M_{\mathrm{n}}$ with conversion (right) for polymerization of methyl methacrylate with [MMA]/[Alkoxyamine] $=100$ using methyl 3-(tert-butyl(1-methoxy-2-methyl-1-oxopropan-2-yloxy)amino)-3-cyano-2,2dimethylpropanoate at $90{ }^{\circ} \mathrm{C}$ as $50 \mathrm{wt} \%$ solution in toluene. 


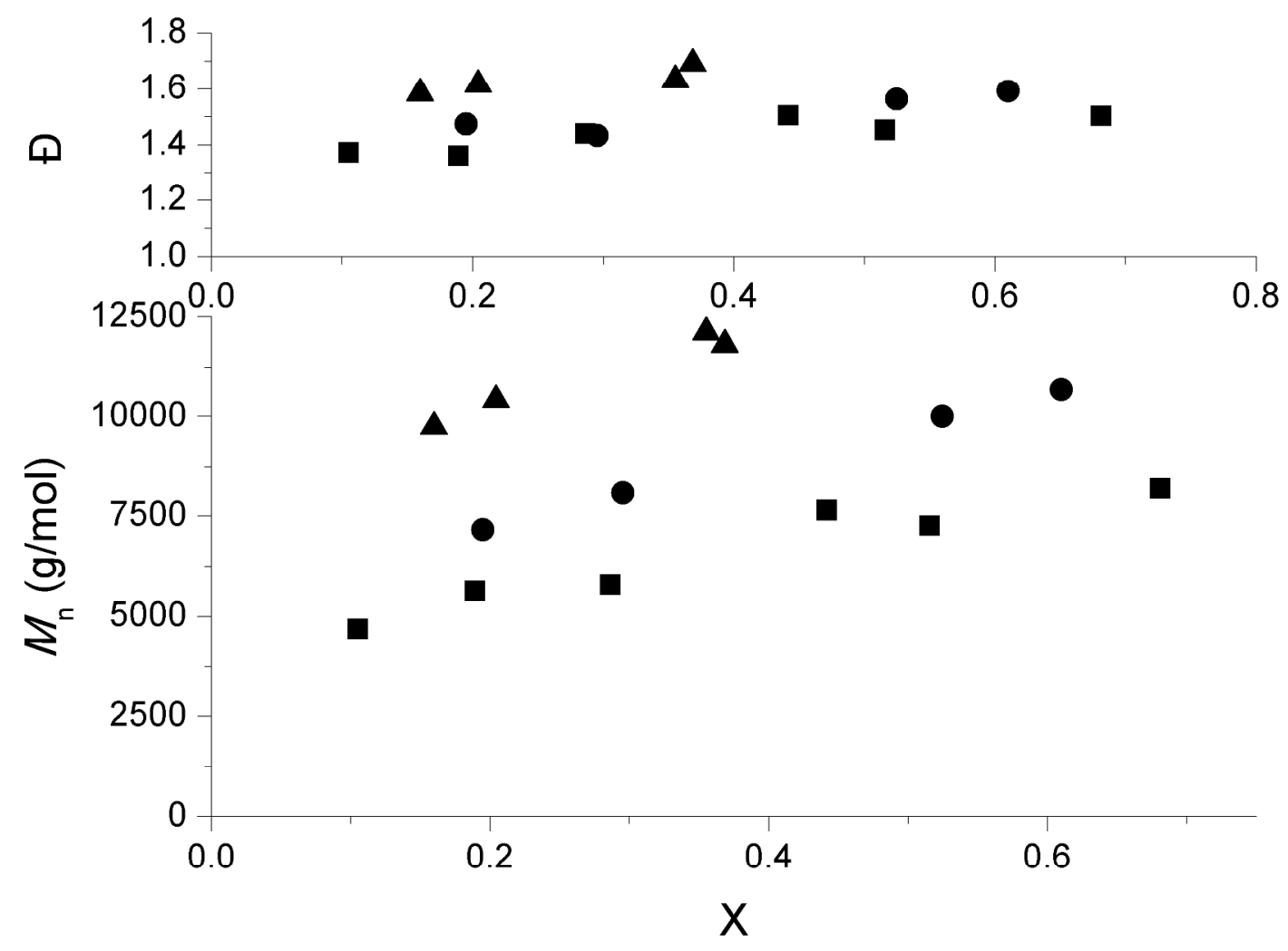

Figure S2 Evolution of molecular weight and dispersity for polymerization of methyl methacrylate for alkoxyamine IV with [MMA]/[Alkoxyamine] = 100 (filled squares), $[\mathrm{MMA}] /[$ Alkoxyamine $]=200($ filled circles $)$ and $[\mathrm{MMA}] /[$ Alkoxyamine $]=400($ filled triangles). 


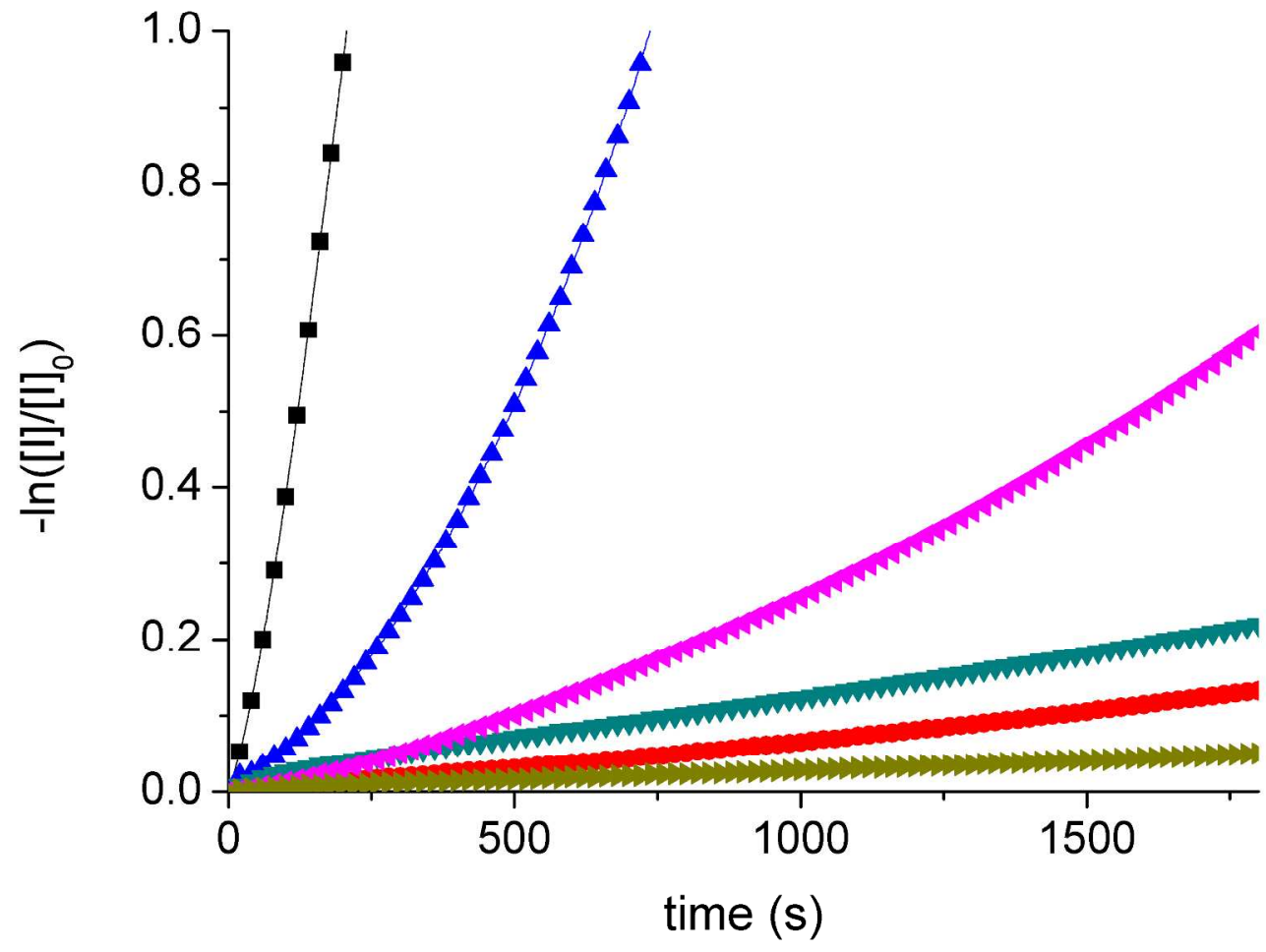

Figure S3 Decomposition of alkoxyamines by radical trapping experiments with Galvinoxyl at $70{ }^{\circ} \mathrm{C}$. Blocbuilder (black squares), alkoxyamine IV terminated poly(methyl methacrylate) (blue triangles), alkoxyamine II (pink triangles), alkoxyamine I (green triangles), alkoxyamine IV (red circles), alkoxyamine III (gold triangles). 
Table S1 Arrhenius parameters and value of decomposition rate coefficient at $90{ }^{\circ} \mathrm{C}$ for various alkoxyamines. ${ }^{a}$

\begin{tabular}{llll}
\hline Alkoxyamine & $\mathbf{A ~ ( \mathbf { s } ^ { - 1 } )}$ & Ea $\left(\mathrm{kJ} . \mathrm{mol}^{-\mathbf{1}}\right)$ & $\boldsymbol{k}_{\boldsymbol{d}, 90}\left(\mathbf{s}^{-\mathbf{1}}\right)^{\mathbf{b}}$ \\
\hline Blocbuilder & $4.3 \times 10^{14}$ & 111 & 0.046 \\
\hline I & $7.4 \times 10^{13}$ & 115 & 0.002 \\
\hline II & $5.2 \times 10^{13}$ & 112 & 0.004 \\
\hline IV & $1.1 \times 10^{13}$ & 112 & 0.001 \\
\hline pMMA-IV & $6.6 \times 10^{13}$ & 109 & 0.014 \\
\hline
\end{tabular}

${ }^{a}$ Due to the very slow decomposition of alkoxyamine III at low temperatures the values for $k_{d}$ at temperatures lower than $70{ }^{\circ} \mathrm{C}$ could not be obtained and therefore the Arrhenius parameters are not included. At higher temperatures the decomposition of galvinoxyl can affect the accurate measurement of $k_{d}$ by the present method.

${ }^{\mathrm{b}}$ Rate coefficient for alkoxyamine decomposition at $90{ }^{\circ} \mathrm{C}$ estimated from the Arrhenius parameters. 


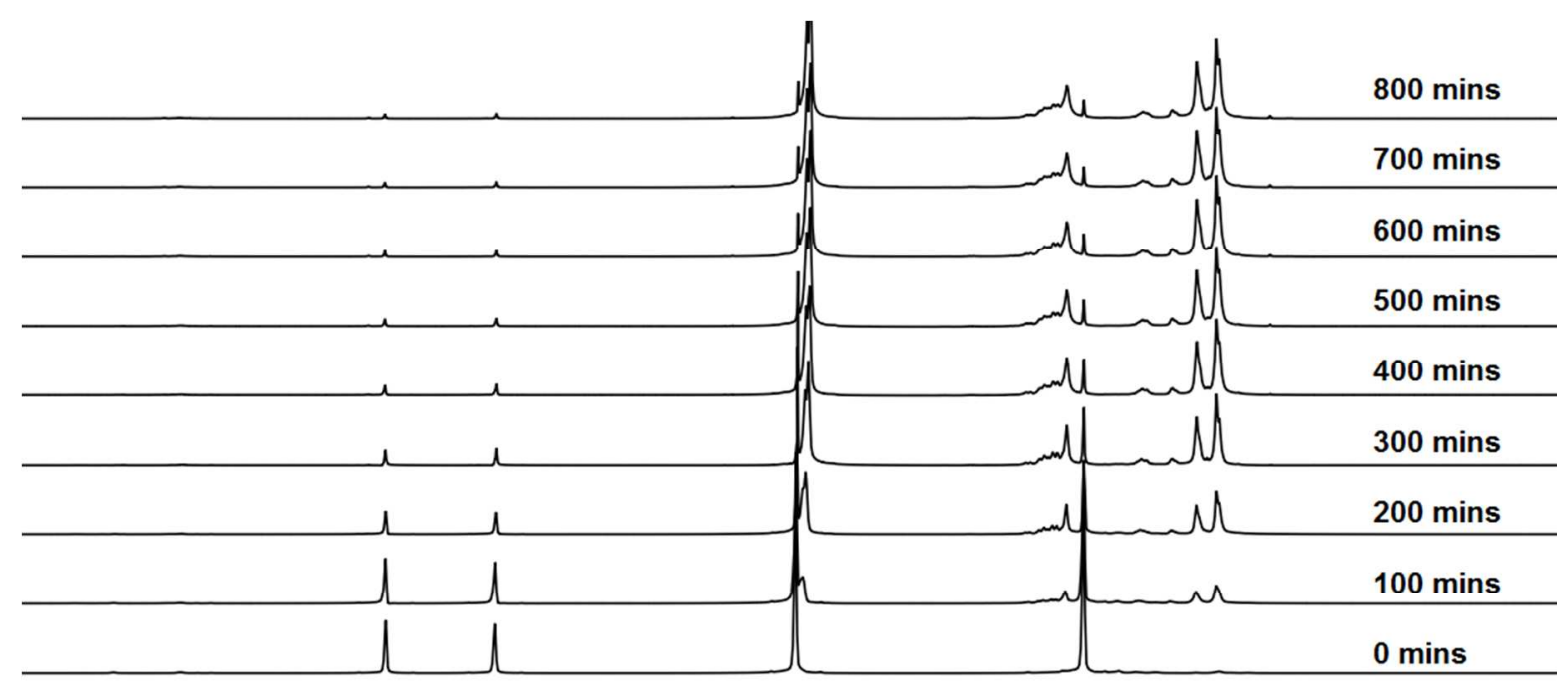

$\begin{array}{lllllllllllllllllll}3.0 & 7.5 & 7.0 & 6.5 & 6.0 & 5.5 & 5.0 & 4.5 & 4.0 & 3.5 & 3.0 & 2.5 & 2.0 & 1.5 & 1.0 & 0.5 & 0.0 & -0.5 & -1\end{array}$ f1 (ppm)

Figure S4 Evolution of ${ }^{1} \mathrm{H}$ NMR spectra during the polymerization of methyl methacrylate as $50 \mathrm{wt} \%$ solution in toluene- $\mathrm{d}_{8}$ in the presence of alkoxyamine IV $\left([\mathrm{M}]_{0} /[\mathbf{I V}]=100\right)$. 


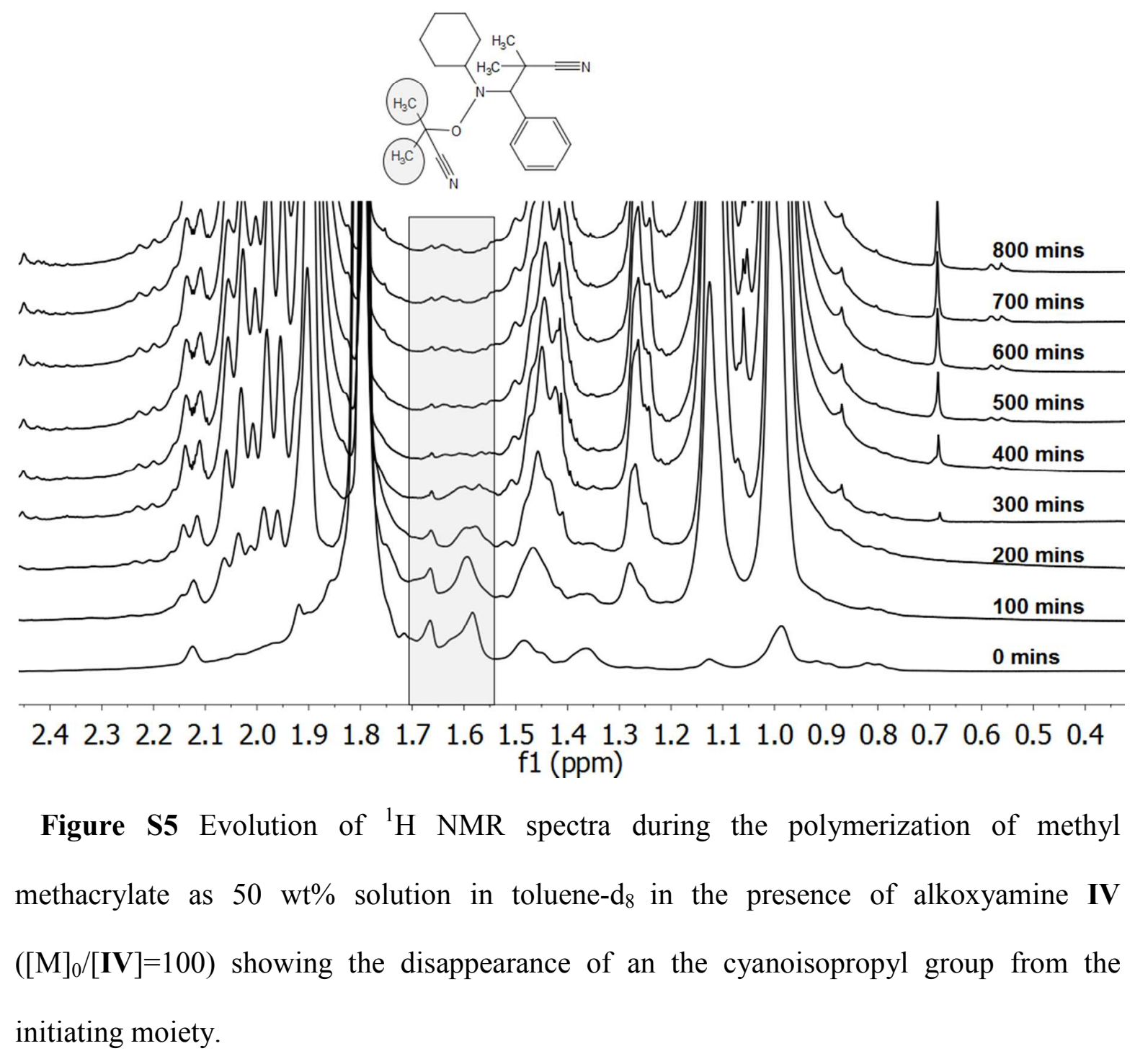




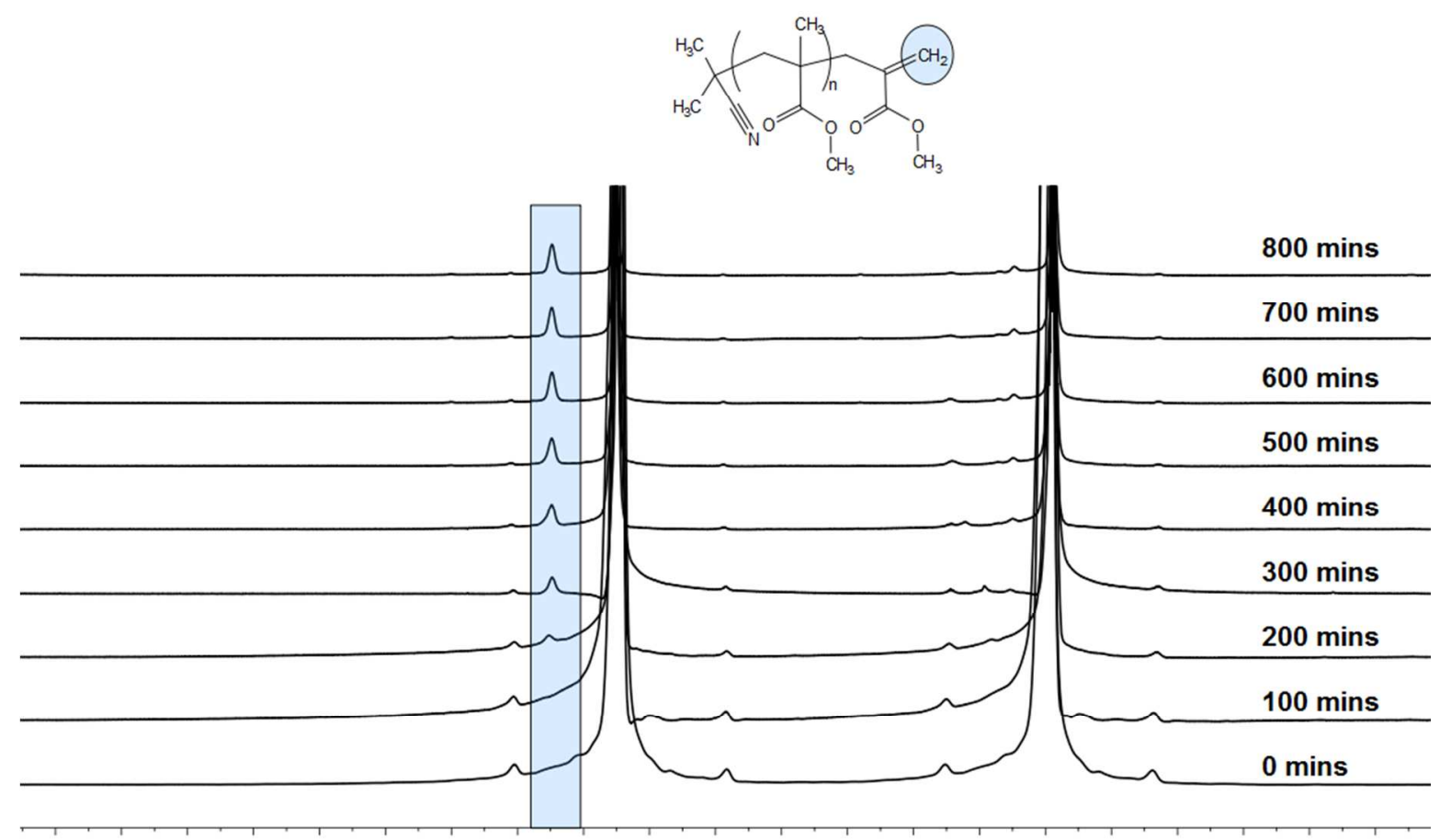

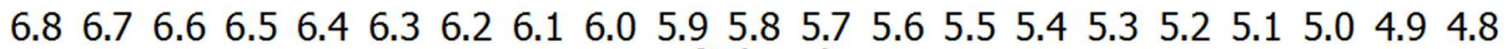
f1 (ppm)

Figure S6 Evolution of ${ }^{1} \mathrm{H}$ NMR spectra during the polymerization of methyl methacrylate as $50 \mathrm{wt} \%$ solution in toluene- $\mathrm{d}_{8}$ in the presence of alkoxyamine IV $\left([\mathrm{M}]_{0} /[\mathbf{I V}]=100\right)$ showing the appearance of an unsaturated peak at high conversions (highlighted). 


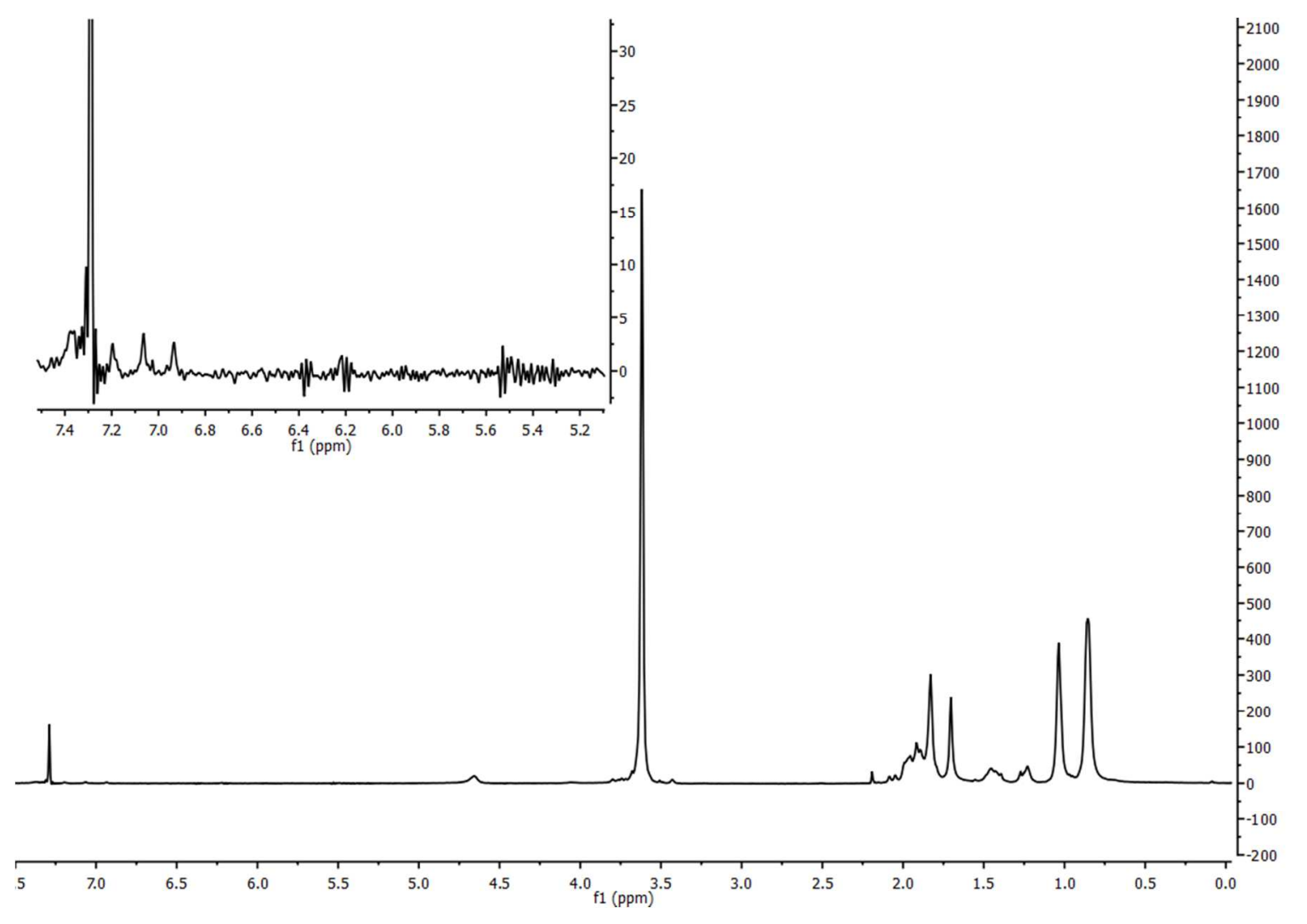

Figure S7 ${ }^{1}$ H NMR spectrum of poly(methyl methacrylate) produced using alkoxyamine IV after precipitation. Inset shows the region in which signal arising from terminal unsaturations would occur. 


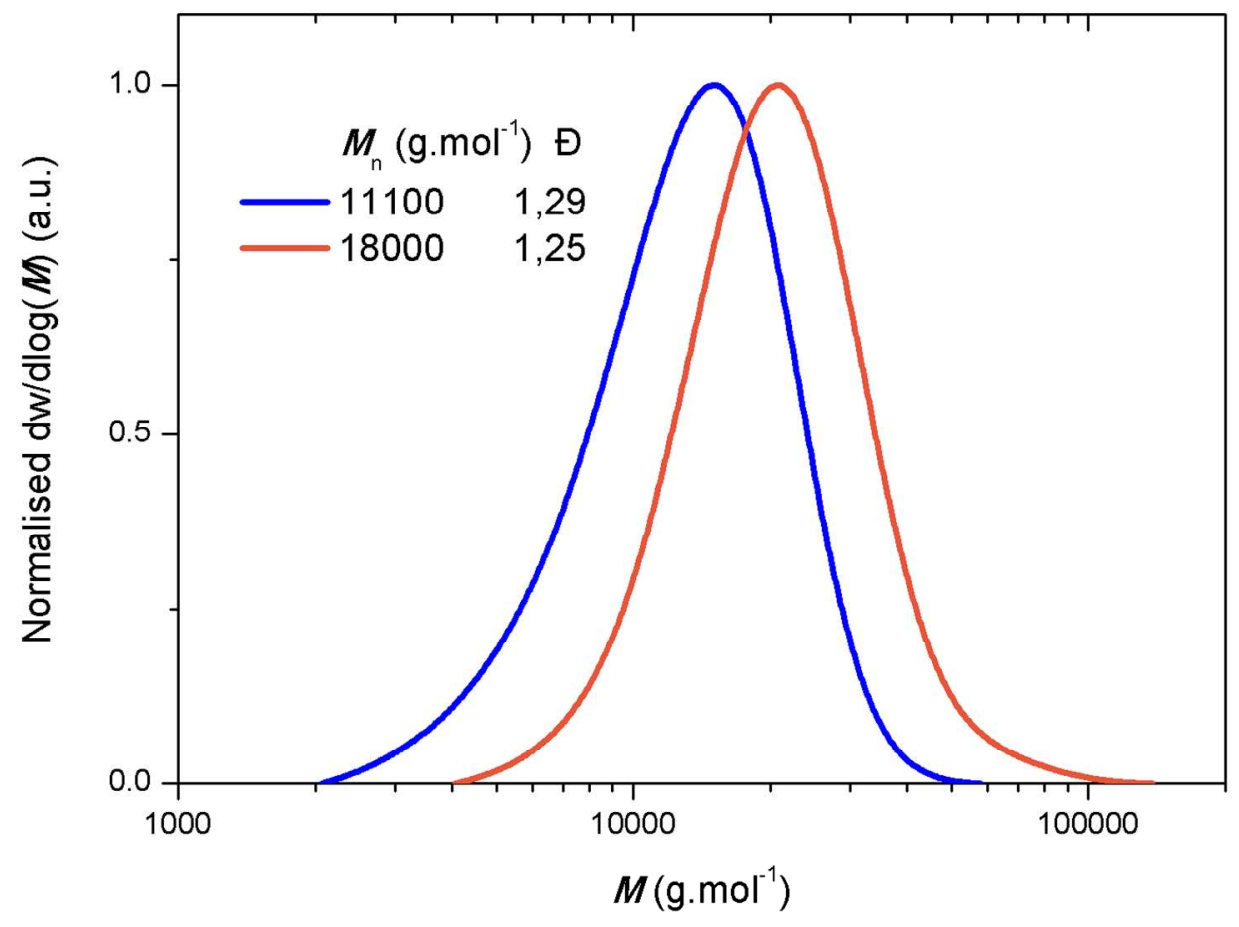

Figure S8 Molecular weight distribution of poly(methyl methacrylate) initiated by alkoxyamine IV with [MMA] / [Alkoxyamine] $=100$ (blue) at $96{ }^{\circ} \mathrm{C}$ and molecular weight distribution after chain extension with butyl methacrylate (red). 

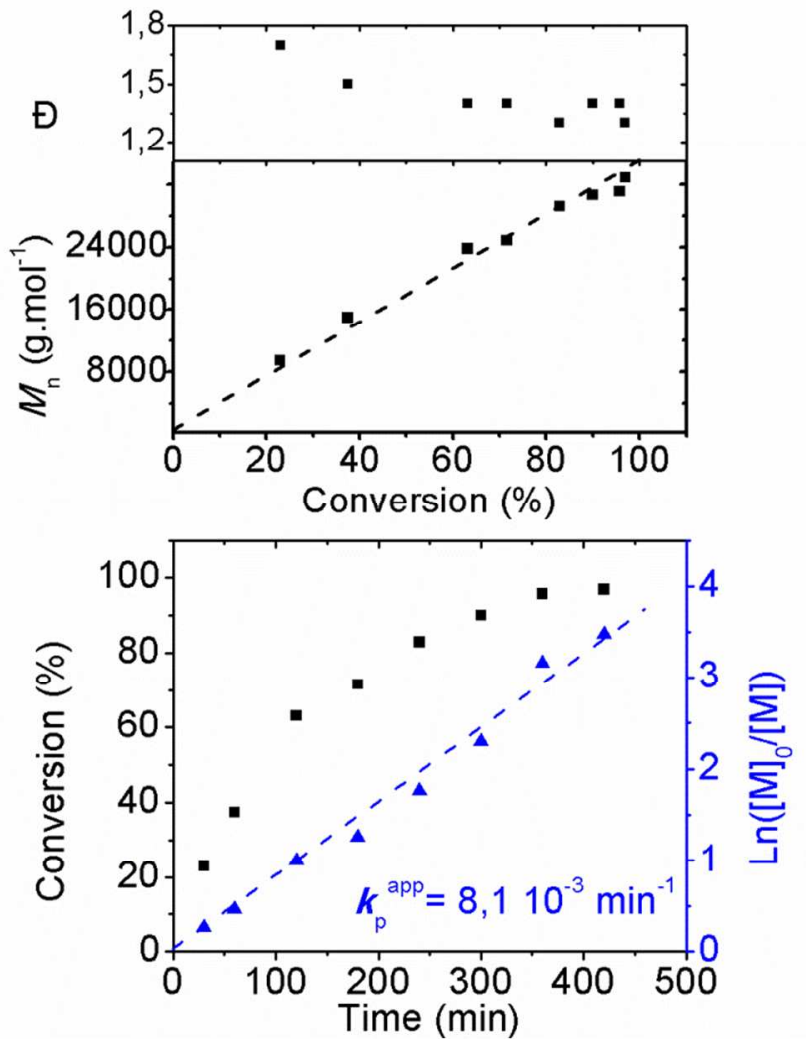

Figure S9 Evolution of conversion, molecular weight and dispersity (measured by SEC-

MALLS) for polymerization of styrene for alkoxyamine IV with [Styrene]/[Alkoxyamine] $=333$ conducted at $75 \mathrm{wt} \%$ in tert-butyl benzene at $126^{\circ} \mathrm{C}$. 